\title{
Video Article \\ Mouse Islet of Langerhans Isolation using a Combination of Purified Collagenase and Neutral Protease
}

\author{
Natalie D. Stull ${ }^{1}$, Andrew Breite ${ }^{2}$, Robert McCarthy ${ }^{2}$, Sarah A. Tersey ${ }^{1}$, Raghavendra G. Mirmira ${ }^{1,3,4}$ \\ ${ }^{1}$ Department of Pediatrics and the Herman B Wells Center for Pediatric Research, Indiana University School of Medicine \\ ${ }^{2}$ VITACYTE, LLC \\ ${ }^{3}$ Department of Medicine, Indiana University School of Medicine \\ ${ }^{4}$ Department of Cellular and Integrative Physiology, Indiana University School of Medicine
}

Correspondence to: Raghavendra G. Mirmira at rmirmira@iupui.edu

URL: https://www.jove.com/video/4137

DOI: doi:10.3791/4137

Keywords: Cellular Biology, Issue 67, Islet, collagenase, mouse, insulin, fluorescence

Date Published: 9/7/2012

Citation: Stull, N.D., Breite, A., McCarthy, R., Tersey, S.A., Mirmira, R.G. Mouse Islet of Langerhans Isolation using a Combination of Purified Collagenase and Neutral Protease. J. Vis. Exp. (67), e4137, doi:10.3791/4137 (2012).

\section{Abstract}

The interrogation of beta cell gene expression and function in vitro has squarely shifted over the years from the study of rodent tumorigenic cell lines to the study of isolated rodent islets. Primary islets offer the distinct advantage that they more faithfully reflect the biology of intracellular signaling pathways and secretory responses. Whereas the method of islet isolation using tissue dissociating enzyme (TDE) preparations has been well established in many laboratories ${ }^{1-4}$, variations in the consistency of islet yield and quality from any given rodent strain limit the extent and feasibility of primary islet studies. These variations often occur as a result of the crude partially purified TDEs used in the islet isolation procedure; TDEs frequently exhibit lot-to-lot variations in activity and often require adjustments to the dose of enzyme used. A small number of reports have used purified TDEs for rodent cell isolations ${ }^{5,6}$, but the practice is not widespread despite the routine use and advantages of purified TDEs for human islet isolations. In collaboration with VitaCyte, LLC (Indianapolis, IN), we developed a modified mouse islet isolation protocol based on that described by Gotoh ${ }^{7,8}$, in which the TDEs are perfused directly into the pancreatic duct of mice, followed by crude tissue fractionation through a Histopaque gradient ${ }^{9}$, and isolation of purified islets. A significant difference in our protocol is the use of purified collagenase (Clzyme MA) and neutral protease (Clzyme BP) combination. The collagenase was characterized by the use of $a^{6}$ fluorescence collagen degrading activity (CDA) assay that utilized fluorescently labeled soluble calf skin fibrils as substrate ${ }^{6}$. This substrate is more predictive of the kinetics of collagen degradation in the tissue matrix because it relies on native collagen as the substrate. The protease was characterized with a sensitive fluorescent kinetic assay ${ }^{10}$. Utilizing these improved assays along with more traditional biochemical analysis enable the TDE to be manufactured more consistently, leading to improved performance consistency between lots. The protocol described in here was optimized for maximal islet yield and optimal islet morphology using C57BL/6 mice. During the development of this protocol, several combinations of collagenase and neutral proteases were evaluated at different concentrations, and the final ratio of collagenase:neutral protease of 35:10 represents enzyme performance comparable to Sigma Type XI. Because significant variability in average islet yields from different strains of rats and mice have been reported, additional modifications of the TDE composition should be made to improve the yield and quality of islets recovered from different species and strains.

\section{Video Link}

The video component of this article can be found at https://www.jove.com/video/4137/

\section{Protocol}

\section{A. Materials Needed: See Table 1 (reagents) prior to preparation}

1. $\mathrm{HBSS}(\mathrm{P} / \mathrm{S}): 100 \mathrm{ml}$ 10X HBSS $+900 \mathrm{ml} \mathrm{H} \mathrm{H}_{2}+1 \%$ Penicillin/Streptomycin (stored in the refrigerator or kept on ice).

2. $20 \% \mathrm{BSA}$ stock is made in water and aliquoted and stored at $-20{ }^{\circ} \mathrm{C}$

3. HBSS(BSA): $200 \mathrm{ml} 1 \mathrm{X} \mathrm{HBSS}(\mathrm{P} / \mathrm{S})+3 \mathrm{ml}$ of $20 \% \mathrm{BSA}$ (final BSA concentrations is $0.3 \%$ )

4. Islet medium: RPMI $+10 \%$ FBS $+1 \%$ glutamine $+1 \%$ Penicillin/Streptomycin

5. Histopaque 1100: $240 \mathrm{ml} 1119$ Histopaque $+200 \mathrm{ml} 1077$ Histopaque

6. 4-0 Suture (McKesson): cut into $2 \frac{3 / 4}{4}$ inch pieces and stored in a $10 \mathrm{~cm}$ Petri dish

7. Instruments: Bend the forceps from Fine Science Tools to $90^{\circ}$, and file down the serrated teeth of all three pairs of the forceps. The goal is to dull the teeth, not to remove them.

8. Cannula for administration of collagenase/protease mixture: $27 \mathrm{G} 1 / 2$ in. needle, $301 / 2$ in. needle, PE50 tubing cut into 12 in. pieces. File both needles down to a smooth rounded end that has no sharp edges. Insert the $27 \mathrm{G}$ needle into one end of a 12 in. piece of PE50 tubing. Remove the $30 \mathrm{G}$ needle from the casing by smashing the casing with a pair of pliers, turning the casing $1 / 4$ turn each time. Remove the needle with the pliers from the casing and insert it into the other end of the PE50 tubing under a dissection microscope. Be sure to not kink the tubing as you insert the needle into the PE50 tubing. The $27 \mathrm{G}$ needle is the end that you will attach the syringe of collagenase. 
9. Collagenase (Clzyme MA) and Neutral Protease (Clzyme BP). Reconstitute the TDE per manufacturer's instructions. Refer to the lot specific Certificate of Analysis to calculate the enzyme activity concentration. Transfer a total of 350,000 collagen degrading activity (CDA) units of the reconstituted collagenase and 100,000 neutral protease units of the reconstituted BP Protease into a conical tube and dilute up to $15 \mathrm{ml}$ total in HBSS (P/S)

\section{B. Step-by-Step Protocol}

\section{Inflation of Pancreas with Collagenase/Protease Mixture}

1. Euthanize mouse by cervical dislocation, saturate the mouse torso with $70 \% \mathrm{EtOH}$, open abdominal cavity completely from anus to diaphragm with any dissection scissors and forceps.

2. Place the mouse on the platform of a dissection microscope.

3. Pull the caecum and ascending colon out and set them outside the body cavity to your left. See Figure $\mathbf{1}$ for a summary of the following steps.

4. Position the lobes of the liver against the diaphragm; they should remain there if the body cavity is open far enough. Find the hepatic artery, portal vein and bile duct bundle leading into the liver by gripping the duodenum with curved forceps. With another pair of curved forceps, reach under the artery, vein, and duct bundle and pull a $23 / 4$ in. piece of $4-0$ suture under the artery, vein, bile duct and tie it once and pull it tight as close to the liver as possible.

5. Using two pairs of curved forceps, carefully grab the duodenum and find the bile duct attached to the duodenum at the papilla. Use a tong of the forceps to poke through the pancreas and connective tissue right under the bile duct close to the papilla. Poke your forceps quickly through the organ to make a hole and then put both tongs of forceps through and grab another $23 / 4$ inch piece of $4-0$ suture through and tie it once and pull it to a small circle, but do NOT pull tight.

6. Change to the $90^{\circ}$ forceps and to the Superfine Vannas scissors. With the $90^{\circ}$ forceps, carefully pinch and pull the small intestine until the bile duct is taut. Make one horizontal cut across the papilla with the scissors by stabbing the open scissors into the intestine and then cutting with one motion. Try to only make one cut across the papilla without dislodging the bile duct from the papilla.

7. While still holding the intestine with the $90^{\circ}$ forceps, insert the cannula into the bile duct up to half the length of the bile duct, and then gently pull the suture tight around the cannula.

8. Fill a $3 \mathrm{ml}$ syringe with $2.0 \mathrm{ml}$ of collagenase/protease mixture and inject into the cannula at a slow, constant pace.

9. After inflation of the pancreas is complete, remove cannula from bile duct and use the curved forceps and curved spring scissors to remove the inflated pancreas by starting at the descending colon and snipping the connective tissue as you pull the intestines up. Continue to remove the pancreas from the intestines until you reach the bile duct, then remove the pancreas from the spleen, then the stomach and then from the viscera of the abdominal cavity. Finish removing by snipping away the sutures. Add the pancreas to a $50 \mathrm{ml}$ tube containing $5 \mathrm{ml}$ of HBSS(P/ S). This tube should be on ice.

10. Repeat the procedure above for each animal up to four animals. For optimal results, dissociate only four pancreata at one time. Typically, while the first four are in the $37^{\circ} \mathrm{C}$ water bath, we inflate another four pancreata.

\section{Pancreas Dissociation}

1. Place the $50 \mathrm{ml}$ tubes containing the pancreata into a $37^{\circ} \mathrm{C}$ water bath for $15 \mathrm{~min}$.

2. Gently rock the tube and check for tissue dissociation, be sure tissue comes apart easily, then swirl the tubes 12 times while you are holding the tube by the lid.

3. Add no more than $30 \mathrm{ml}$ of HBSS(BSA) (this can be a lower amount, depending on how much is required to balance the tubes for the centrifugation step), and centrifuge at $290 \mathrm{x}$ g for one min.

4. Aspirate supernatant carefully and leave a small amount of supernatant $(2-3 \mathrm{ml})$ at the bottom so as to not disrupt the cell pellet.

5. Using a $30 \mathrm{ml}$ syringe attached to $14 \mathrm{G}$ needle, add no more than $10 \mathrm{ml}$ of $\mathrm{HBSS}(\mathrm{BSA})$ and aspirate the suspension up and down 2 times.

6. Filter the cell mixture through a plastic tea strainer into a $50 \mathrm{ml}$ tube and rinse with another $10 \mathrm{ml} \mathrm{HBSS}(\mathrm{BSA})$.

7. Centrifuge at $330 \mathrm{xg}$ for $2 \mathrm{~min}$.

8. Decant supernatant and invert tubes to drain on an absorbent paper towel for $1 \mathrm{~min}$.

9. Resuspend each tube in $10 \mathrm{ml}$ cold 1100 histopaque.

10. Overlay the histopaque with $10 \mathrm{ml} \mathrm{HBSS(BSA)}$ and centrifuge at $900 \mathrm{xg}$ for $18 \mathrm{~min}$.

11. Remove the entire $20 \mathrm{ml}$ of supernatant using a large bore $25 \mathrm{ml}$ pipet and pass the supernatant through an inverted $70 \mu \mathrm{m}$ filter.

12. Rinse the islets into a $10 \mathrm{~cm}$ Petri dish by pipetting $10 \mathrm{ml}$ islet media through the filter while holding it right side up over the dish.

13. Culture the islets in a $37^{\circ} \mathrm{C}, 5 \% \mathrm{CO}_{2}$ tissue culture incubator until ready for experimentation. Typically, islets are hand-picked and counted prior to experimentation.

\section{Representative Results}

Islet yields, morphology, and quality are the general parameters used to judge the success of islet isolation. In our hands, islet yields from the average C57BL/6 mouse are in the range of 150-250 islets using this protocol (see Table 2), and are comparable to data obtained using optimized Sigma type XI collagenase. However, yields can vary depending upon the mouse strain used and the age of the mouse. Most of the animals we employ are in the 8-16 week age range This protocol has been tested on multiple mouse strains, including C57BL/6 (180-250 islets/ mouse), CD1 (200-300 islets/mouse), 129/B6 (200-300 islets/mouse), BLKS-db/db (120-200 islets/mouse), NOD (10 week-old, 100-150 islets/ mouse), and NOD-SCID (100-150 islets/mouse). Typical islet morphology is shown in Figure 2, in which islets have a round to oblong shape with relatively uniform size (although size uniformity can vary from strain to strain). Figure 3 shows our typical analysis of glucose-stimulated insulin secretion from C57BL/6 mouse islets isolated using purified TDEs vs. Sigma type XI collagenase. Typically, a high quality islet preparation results in an insulin stimulation at $25 \mathrm{mM}$ glucose that is $6-20$ times greater than that observed at $2.5 \mathrm{mM}$ glucose. Other applications can also 
be used to test the quality of isolated islets, and these include use of perifusion techniques, $\mathrm{Ca}^{2+}$ imaging (with Fura2), and reverse-transcription PCR, among others ${ }^{11}$.

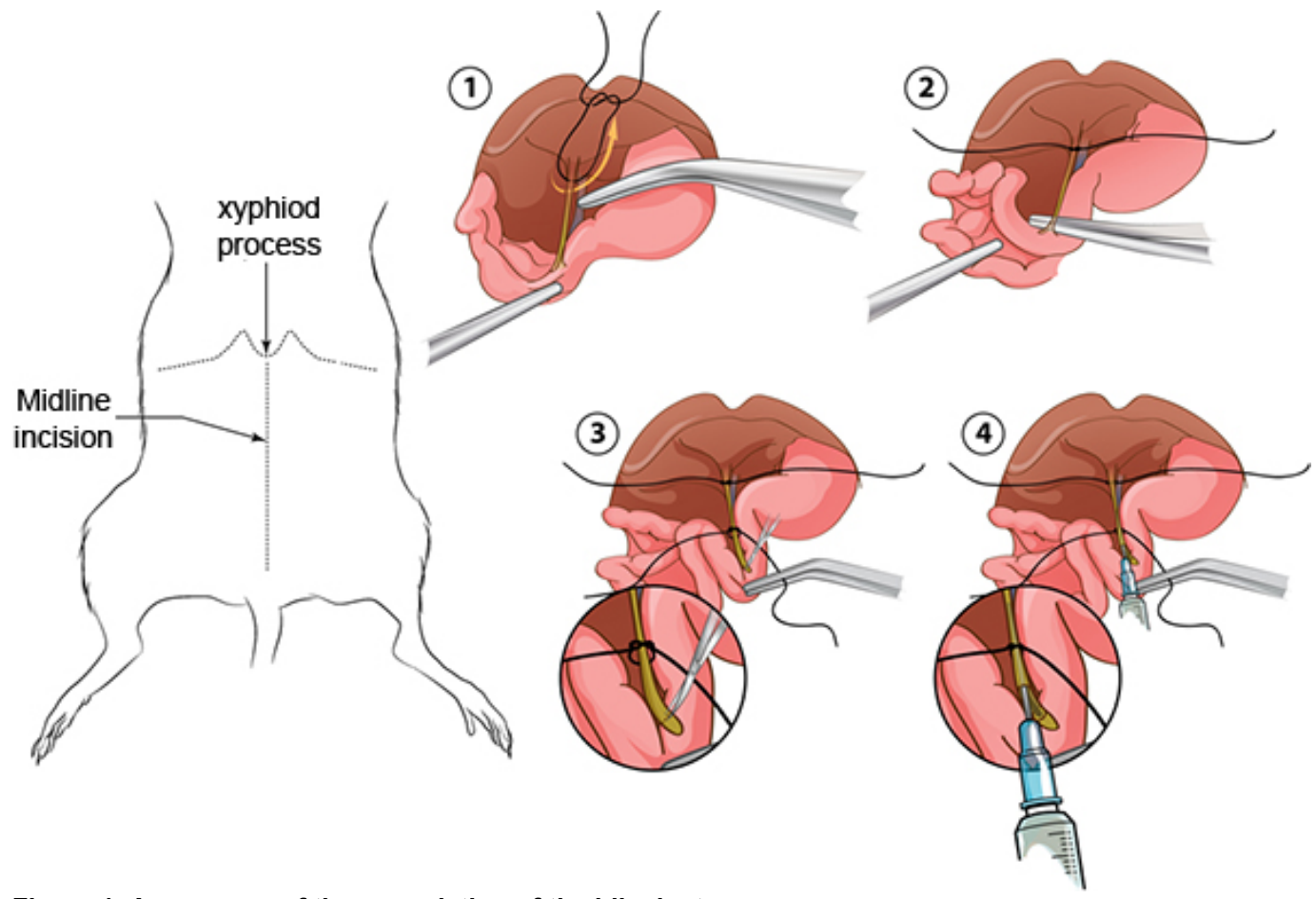

Figure 1. A summary of the cannulation of the bile duct.

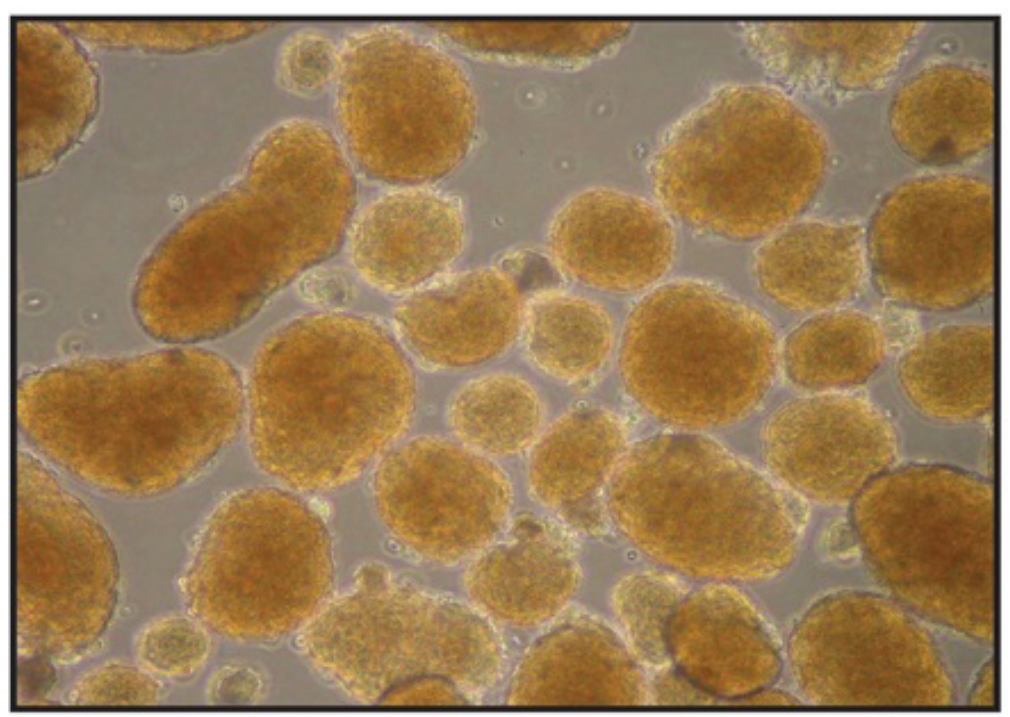

Figure 2. Typical appearance of C57BL/6 islets at $24 \mathrm{hr}$ following isolation. Images were acquired on an inverted microscope at $40 \mathrm{X}$ magnification. 


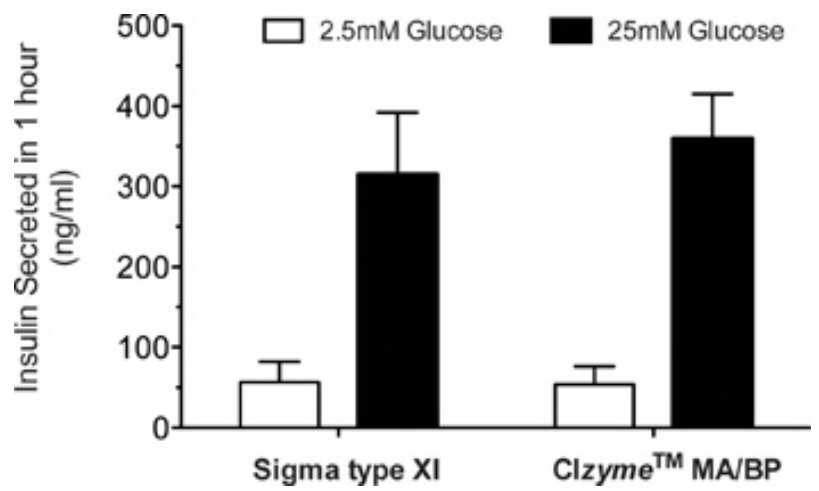

Figure 3. Glucose-stimulated insulin secretion of C57BL/6 islets. At $24 \mathrm{hr}$ following isolation, 100 islets were incubated in a 12-well dish for $1 \mathrm{hr}$ at $37^{\circ} \mathrm{C}$ in Krebs-Ringer HEPES-buffered solution containing $2.5 \mathrm{mM}$ glucose. Islets were then transferred to Krebs-Ringer HEPES at 2.5 $\mathrm{mM}$ glucose for an additional hr, after which the supernatant was collected for insulin measurement using a two-site immunospecific enzymelinked immunosorbent assay (ELISA) (Crystal Chem). The same islets were subsequently transferred to Krebs-Ringer HEPES-buffered solution containing $25 \mathrm{mM}$ glucose, and insulin release into the medium was measured by ELISA after $1 \mathrm{hr}$ of incubation.

\section{Discussion}

In this protocol, we have described our procedure for the cannulation, collagenase perfusion, and dissociation of the murine pancreas, with the goal of isolating the islets of Langerhans. Technically, our method, once mastered, should allow for pancreas isolation within 4 min of euthanizing the animal, and by $1 \mathrm{hr}$ should result in the isolation of islets from a single animal. The rapidity of the technique allows us to isolate islets from up to 12 mice at a typical stretch, thereby resulting in the isolation of up to 3,000 islets.

Unlike other protocols that use crude preparations of collagenase, our protocol features the use of purified proteases, Clzyme Collagenase MA and Clzyme BP Protease. Variations in the consistency of TDE preparations that are commercially available requires that each lot be individually tested and optimized prior to general use. This lot-to-lot variability led us to consider use of purified TDEs from VitaCyte. These highly purified TDEs are characterized by multiple methods including the use of sensitive fluorescence labeled substrate assays. The fluorescence CDA assay is more sensitive to different molecular forms of collagenase that have different kinetics in degrading native collagen. Historical peptide substrate assays provide an incomplete assessment of collagenase. Characterizing collagenase by multiple methods ensures greater enzyme activity between lots.

Based on our in-house testing using a variety of collagenase preparations commercially available, we found that the purified enzyme combinations yielded reproducible lot-to-lot results. The major advantages of using highly purified and rigorously characterized TDEs in this application are once the optimal enzyme composition is defined, the lot-to-lot performance consistency is assured. This consistency eliminates the labor intensive process of lot qualification normally required for crude or enriched collagenase products. Purified TDEs also enable additional modifications of the composition to improve the yield and quality of islets recovered from different mouse strains. Reporting optimal enzyme compositions for isolation of islets from different strains of mice can be more effectively communicated. This, in turn, leads to more productive use of resources and improved flexibility in experimental design.

There are many critical steps that can affect the outcome of islet isolations using our protocol. The first is the need to achieve effective inflation of the pancreas during the perfusion of the enzyme preparation. It is important to start inflation with gentle force on the syringe, and increase the force as the pancreas inflates. It is helpful to move the intestines and lift the pancreas during inflation so that the collagenase perfuses the entire organ. Another critical step is the force with which one shakes the tubes after incubation at $37^{\circ} \mathrm{C}$ (step 2.2). We have found that shaking the pancreas hard against the cap of the tube causes fragmentation of islets, but without any form of mechanical dissociation at this step, islet yields can fall dramatically. It is also imperative that during the dissociation step with the syringe (step 2.5), a medium-level force is applied during the up and down motion with the plunger; this ensures adequate tissue dissociation before the filtering step (2.6), where very little tissue should be retained on the tea strainer filter. Finally, the last step to follow carefully is the aspiration of the entire $20 \mathrm{ml}$ of the histopaque fractionated islets. Although islets are typically at the interface of the histopaque and HBSS, we have found that we lose islets when we try to remove only the interface; instead, we now remove the entire $20 \mathrm{ml}$ using a large bore $25 \mathrm{ml}$ pipet. We added the filtration through the inverted $70 \mu \mathrm{m}$ filter (step 2.11) to eliminate the need to centrifuge the islets repeatedly to wash away the histopaque.

\section{Disclosures}

NDS, SAT, and RGM have nothing to disclose. Author AGB is employed by VitaCyte. Author RCM has an ownership interest in VitaCyte.

\section{Acknowledgements}

This work was supported in part by NIH grants R01 DK060581, R01 DK083583 (both to RGM).

\section{References}

1. Li, D.-S., Yuan, Y.-H., Tu, H.-J., Liang, Q.-L., \& Dai, L.-J. A protocol for islet isolation from mouse pancreas. Nat. Protoc. 4, 1649-1652 (2009). 
2. Szot, G.L., Koudria, P., \& Bluestone, J.A. Murine pancreatic islet isolation. J. Vis. Exp. 7, e255, DOI: 10.3791/255 (2007).

3. Zmuda, E.J., Powell, C.A., \& Hai, T. A method for murine islet isolation and subcapsular kidney transplantation. J. Vis. Exp. 50, e2096, DOI: 10.3791/2096 (2011).

4. Kin, T., O'Gorman, D., Senior, P., \& Shapiro, A.M.J. Experience of islet isolation without neutral protease supplementation. Is/ets. 2, 278-282 (2010).

5. Gramignoli, R., Green, M.L., Tahan, V., Dorko, K., Skvorak, K.J., Marongiu, F., Zao, W., Venkataramanan, R., Ellis, E.C.S., Geller, D., Breite, A.G., Dwulet, F. E., McCarthy, R.C., \& Strom, S.C. Development and application of purified tissue dissociation enzyme mixtures for human hepatocyte isolation. Cell Transplant. DOI: 10.3727/096368911X600939 (In Press, 2012).

6. McCarthy, R.C., Spurlin, B., Wright, M.J., Breite, A.G., Sturdevant, L.K., Dwulet, C.S., \& Dwulet, F.E. Development and characterization of a collagen degradation assay to assess purified collagenase used in islet isolation. Transplant. Proc. 40, 339-342 (2008).

7. Gotoh, M., Ohzato, H., Porter, J., Maki, T., \& Monaco, A.P. Crucial role of pancreatic ductal collagenase injection for isolation of pancreatic islets. Horm. Metab. Res. Suppl. 25, 10-16 (1990).

8. Ohzato, H., Gotoh, M., Monden, M., Dono, K., Kanai, T., \& Mori, T. Improvement in islet yield from a cold-preserved pancreas by pancreatic ductal collagenase distention at the time of harvesting. Transplantation. 51, 566-570 (1991).

9. McCall, M.D., Maciver, A.H., Pawlick, R., Edgar, R., \& Shapiro, A.M.J. Histopaque provides optimal mouse islet purification kinetics: comparison study with Ficoll, iodixanol and dextran. Islets. 3, 144-149 (2011).

10. Breite, A.G., Dwulet, F.E., \& McCarthy, R.C. Tissue dissociation enzyme neutral protease assessment. Transplant. Proc. 42, 2052-2054 (2010).

11. Evans-Molina, C., Robbins, R.D., Kono, T., Tersey, S.A., Vestermark, G.L., Nunemaker, C.S., Garmey, J.C., Deering, T.G., Keller, S.R., Maier B., \& Mirmira, R.G. PPAR-\{gamma\} Activation Restores Islet Function in Diabetic Mice Through Reduction of ER Stress and Maintenance of Euchromatin Structure. Mol. Cell. Biol. 29, 2053-2067 (2009). 